\title{
From the Editor of Sexuality and Disability: A Look at Sexuality During Medical, Intellectual, Psychiatric and Developmental Conditions in Life
}

\author{
Sigmund Hough
}

Published online: 3 May 2013

(C) Springer Science+Business Media New York 2013

In the June 2013 issue, front-line topics include a look at upper limb deficiency from The Netherlands, multiple sclerosis from Poland, renal transplantation from Turkey, intellectual disability from Poland, elderly women's views about sexual desire during old age from Iran, sexual abuse and offending in Autism Spectrum Disorders from the United States. In addition, we have the opportunity to look at the relationship between sexual quality of life in married Turkish women.

Sexuality and Disability continues to provide original impact articles addressing the mental health and medical aspects of sexuality in relation to rehabilitation, hospital, academic and community settings, publishing up-to-date articles, case studies, clinical practice reports, reviews, featured articles, historical articles, special grand rounds topics, brief research reports and survey data reports. Value benefit is provided to authors through worldwide electronic exposure and professional access, while readership gains from scholarly contributions to advance the field through research, best-practice and educational articles. The refined lens of individual contributions from the local and international community continues to deliver a wealth of information on the topic of sexuality and disability for the reader. Thank you for joining us.

S. Hough $(\bowtie)$

396 Washington Street, Suite 211, Wellesley Hills, MA 02481, USA

e-mail: Sigmund_Hough@hms.harvard.edu 